\title{
Studies on the Use of Tissue Culture for the Bioassay of Staphylococcal Enterotoxin "
}

\author{
NICHOLAS A. MILONE \\ University of Michigan. School of Public Health. Amn Arbor. Michigan
}

(Manuscript received April 7, 1962)

\begin{abstract}
SUMMARY
An attempt was made to develop an assay procedure for staphylococcal enterotoxin based on the possible induction of eytopathogenic effects on several strains of tissue culture cells using enterotoxin preparations of varying degrees of purity produced in a laboratory medium. The results suggest that the eruder preparations contained a thermolabile cytotoxie material that is removed in whole or in part with progressive purification. No observable cytopathogenic effect conld be attributed directly to the enterotoxin.
\end{abstract}

\section{INTRODUCTION}

The need for a simple, adequate and specific assay for staphylococcal enterotoxin remains acute (Casmain, 1958) even though recently introduced serologic procedures of fer some hope for a practical test for this toxin (Casman, 1960). Accordingly, we are investigating the use of tissue culture for this purpose.

Any investigation of staphylococcal enterotoxin is faced with a variety of complicating factors. Of the toxic moieties produced by staphylococci and given orally to rhesus monkeys, only enterotoxin causes vomiting (Bergdoll ot al., 1959). When administered parcnterally, however, not only the enterotoxin but occasionally the alpha- and betahemolysins elicit emesis, necessitating the removal or neutralization of hemolysins when this method of enterotoxin assay is used (Casman, 1958).

Quantitative differences in enterotoxin production by different subcultures of the same strain of staphylococcus have been demonstrated (Sugiyama et al., 1960). Worthy of note is the occurrence, in relatively small anounts, of a non-liemolytic heat-labile and dialyzable product of staphy-

\footnotetext{
"This paper was presented before the Laboratory Section of the American Public H.calth $\Lambda$ ssociation at the 89th Annual Meeting in Detroit, Michigan, November 16, 1961.
}

lococcal growth not producing heat-resistant enterotoxin but capable, after treatment with antialpha- and antibeta-hemolysins, of inducing emesis when injected into cats or ingested by monkeys (Casman, 1960). The frequently observed reduction in enterotoxicity of culture filtrates after heating may conceivalbly be due to selective destruction of this material or partial inactivation of the relatively heat-resistant enterotoxin (Casman, 1960).

There have been indications that some enterotoxins are more heat-susceptible than others, and they may also vary in potency. Of some concern is the finding that, using gel-diffusion technique, S6 entcrotoxin produced in food materials did not react with antibody to laboratory-produced enterotoxin (Bergdoll, 1960a).

It has been reported (Vicari et al., 1960) that several bacterial toxins inhibit the growth of tissue cells in culture and that this action can be neutralized by specific antitoxins. However, Lamanna (1959) observes that tissue cultures of mammalian cells are unaffected by botulinal toxins. He cautions that presumed effects of neurotoxins in tissue culture may be attributable to cxtrancous impuritics, not to the neurotoxin itself, and that prevention throngh contact with antitoxin of an observed effect in tissue culture does not of itself constitute proof of toxin activity, since antitoxins as generally 
prepared contain antibodies against intpurities.

Nevertheless. HeLa cells challenged with graded concentrations of crude filtrates obtained from both laboratory medium and custards seeded with enterotoxigenic and nonenterotoxigenic strains of staphylococci exhibited adverse reactions that appeared at significantly carlicr incubation times with the enterotoxigenic strains (Allen, 1961).

Furthermore, staphylococcal alpha-, beta-, and delta-hemolysins and highly purified enterotoxin shown to be free of detectable enzymes and of cross-contamination with other lytic material, when added in graded concentrations, have been reported to affect embryonic heart fibroblasts cultivated in completely synthetic medium, producing characteristic cytopathogenic effects that were discincly dillerent for each toxin as inclicated by the MLD, the shape of the toxcity response curve, and the morphology of the degenerating cells (Guerin et al., 1961). Staphylococcal alpha-hemolysin has been reported to be extremely toxic to shin cultures (Lawrence, 1959).

\section{OBJECTIVES}

The immediate objective of this study was the elaboration of a test for detection and assay of staphylococcal enterotoxin. It was felt that the application of tissue-culture methods to the detection of enterotoxin produced in susceptible foods would be premature and unduly complicated. Hence, enterotoxin preparations produced in a laboratory medium of known composition have been used. Even though it is assumed llat nonspecific substances in preparations made from selected foods might interfere with the demonstration and quantification of the enterotoxin, a method of assay for enterotoxin produced in a laboratory medium would permit the study of factors affecting enterotoxin production, an area where information is meager at this time.

The studies described include: 1) observation of the response of several selected cell lines to the action of enterotoxin preparations: 2) determination of the effect of serum in the culture fluid on enterotoxin preparation activity; 3) comparison of cytopathic effects of preparations made from several staphylococcal strains; 4) demonstration of the effect of heating solutions of the test preparations on cellular response; 5 ) attempted neutralization by "specific" antiserum of the tissue-culture reaction to enterotoxin; and 6) comparison of cellular response to the crude preparations with that of the more highly purified materials. It is adnitted that many avenues of investigation were not explored, primarily because of the small quantities of preparations available.

\section{MATERIALS AND METHODS}

Enterotoxin preparations. With one exception (196E, derived from the $196 \mathrm{E}$ strain), all of the enterotoxin preparations were from the $\$ 6$ strain. The preparations and pertinent information were provided by Drs. Merlin S. Bergdoll, Food Research Institute of the University of Chicago, and Dudley P. Glick and Edward J. Schantz, Chemical Corps Biological Laboratories at Fort Detrick, Maryland. The preparations are described by these investigators as follows:

196E. A crude preparation containing approximately $5 \%$ enterotoxin and with a dry weight of 10-90 $\mu \mathrm{g}$ per cat-vomiting dose. This preparation contained both alpha- and beta-hemolysins, but in very small amounts. Almost all of the enterotoxigenic staphylococci of food-poisoning origin studied have been found to produce only the $196 \mathrm{E}$ serologic type of enterotoxin (Casman, 1960).

PB8A. A relatively crude preparation containing approximately $20 \%$ enterotoxin, with little if any beta-hemolysin and only a small amount of alpha-henolysin. Six of 6 monkeys vomited when orally fer $100 \mu \mathrm{g}$ of this material, 8 of 12 vomited with $50 \mu \mathrm{g}$, and 2 of 12 with $30 \mu \mathrm{g}$. As assayed by intravenous injection, the emetic dose was 20-30 $\mu \mathrm{g}$. It has been found to contain biologically active substances other than enterotoxin, such as fibrinolysin, apyrase, alpha-hemolysin, cuagulase, and a hexabarbital hypnosis-potentiating factor. Many of these activities becane considerably diminished with subsequent purification. Of considerable importance to the interpretation of the data obtained in these studies was the statement that further purification of the enterotoxin effected some loss of toxicity, apparently without otherwise affecting the toxin. This inactivation appeared to be related to the removal of some material that stabilized the toxin, which points to the desirability of using as few steps as possible in purification (Bergdoll et al., 1959).

$P B 9 B$. A partially purified preparation from t'ie PB8A material and containing approximately $80 \%$ enterotoxin. Five of 6 monkeys vomited with 
$25 \mu \mathrm{g}$ fed orally, and with $10 \mu \mathrm{g}$ injected intravenously. This preparation was reported to be 3-4 times as potent as PB8A as determined by monkey feeding tests (Bergdoll, 1960b).

D2. A highly purified preparation made directly from $\mathrm{PB} 8 \mathrm{~A}$ by high-speed centrifugation and chromatography containing an estimated $95 \%$ or more enterotoxin. Six-tenths $\mu \mathrm{g}$, and in some instances $0.1 \mu \mathrm{g}$, produced emesis in monkeys on intravcnous injection. On a rclativc basis, $10 \mu \mathrm{g}$ of PB8A equals the hemolysin activity of 1000 $\mu \mathrm{g}$ of D2 (Schantz, 1961). This preparation contained $4 \%$ nitrogen, which is ecjuivalent to about $25 \%$ protein, the remainder being phosphate buffer.

The indicated purity of these preparations should be vicwed with caution since purity is dependent largely on the method used for its determination. All of these preparations contained demonstrable hemolysins although the tests indicated that alphahemolysins were greatly reduced in the highly purified materials. The enterotoxin materials were dissolved in sterile double-distilled water, with subsequent treatment in accordance with the experimental design used. Solutions were made in sterile double-distilled water just before use since on prolonged standing in solution the more highly purified preparations undergo changes that result in their precipitation as insoluble material. It seems plausible to assume that at least sone of the precipitate formed is enterotoxin.

The usual tests for stcrility gave no inclications that the solutions were contaminated. Since Di. Bergdoll found sone apparen loss of toxicity when solutions are filtered through Millipore filter, the preparations used in this study were not filtered.

The serial twofold dilution schedules used were hased on dry weight of the enterotoxin preparation irrespective of estimated enterotoxin content, for reasons that will become apparent later herein. Dilutions were made such that the recuired quantity of test substance was present in $1.0 \mathrm{ml}$ of the tissue-culture maintenance medium.

Controls. It is unfortunate that control preparations derived from nonenterotoxigenic staphylacocci were not available. Dr. Bergdoll informed us that he used one nomenterotoxigenic strain (184) carrying the material only through a partially purified state, i.e, through the first three steps of his procedure: acid precipitation, alumina adsorption, and alcohol precipitation. Approximately the same amount of material was obtained with this strain as with the enterotoxin-producing strains. We do not know if anything would have remained if the preparation had been taken through the complete purification procedure.

An unseeded staphylococcal-medium control would not appear to be of concern here since Dr. Bergdoll was unable to recover anything by extraction and concentration under these conditions.

Some control preparations with nonenterotoxigenic staphylococci were made by us with the method of Casman (1958). Tests with these materials, even with an excess of six times the largest amount of enterotoxin preparation used, had no adverse effects on the cell cultures.

Ccll lines. The cell lines used were tissue-culture cell strains H.Ep \#2 and HeLa, both derived from human carcinomas, and an epithelial strain derived from normal human heart cells. These three cell lines were selected because they gave the most satisfactory indication of toxic effect of the five lines tested, which included human embryonic intestinal mucosa (Henle) and mouse subcutaneous connective tissue cells (LLCM1).

In some of the experiments H.Ep \#2 cells were maintained in Eagle's basal medium (EBM) containing $20 \%$ human serum or $20 \%$ calf serum. FleLa cells were carried in EBM containing 20\% calf serum, and the human heart cells in EBM with $10 \%$ human serum. All media contained penicillin and streptonycin, respectively 100 units and $100 \mu \mathrm{g}$.

Stock solutions were prepared by inoculating milk dilution bottles with $10^{\circ}$ cells in $10 \mathrm{ml}$ of the appropriate medium. The medium was decanted and replaced with fresh medium every third or fourth day. Cells were passaged using $0.005 \mathrm{M}$ versene every $8-12$ days. Test cultures were prepared in $16 \times 120-\mathrm{mm}$ screw-capped tubes as folluws:

The cells were removed from the stock bottles with versene, centrifuged, washed in Hanks' halanced salt solution, and suspended in growth medium. After counting, the suspension was diluted in medium to approximately $6.0 \times 10^{-1}$ cells per $\mathrm{ml}$, and $1.0 \mathrm{ml}$ of suspended cells was transferred to each tube. Aftcr the cultures were incubated for three days they were prepared for the tests by removing the growth medium and washing with Hanks' balanced salt solution. Dilutions of the test preparation in $1.0 \mathrm{ml}$ of the appropriate medium were then added to the tube cultures. With few exceptions all tubes were set up in quadruplicate in the tests. Some of the experiments were conducted with Medium 199. For these, cells were propagated in Eagle's medium with serum whereas the titrations were performed with Medium 199.

\section{RESULTS}

Early in this investigation the metaholic inhibition test was used as indicator of effect. This rather simple approach tended to be sensitive to a multitude of factors, however, giving rise to 

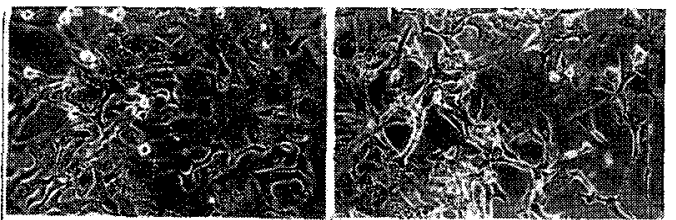

A

B



C

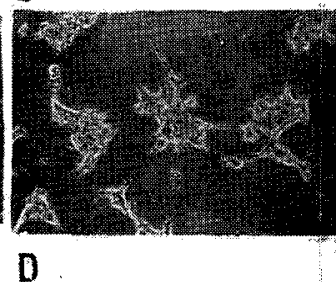

Fig. 1. Photomicrographs of cytopathogenic effect with time $(\times 125)$.

erratic and many times inconclusive results. It was determined that cytopathology as observed by light microscopy showed a more reproducible effect of the toxic preparations.

Cytopathogenic effect. Photonicrographs of H.Ep\#2 cells exposed to the enterotoxic material for 3 days in a perfusion chamber, taken at 2to 5-min intervals followed by longer periods toward the end of the exposure period, help characterize the cytopathogenic effects. Fig. 1-A shows the appearance of the cells in growth medium before any adverse effect is discernible. Fig. 1-B,C,D presents the evidence of progressive cytotoxic effects with time, culminating in the pronounced effect shown in D at the end of the 3-day exposure period. The action follows a pattern indicating retraction of cytoplasm followed by cell detachment from the substrate along with some clumping of what appear to be unhealthy cells. Near the end of the exposure period few rounded cells remain on the glass substrate. This residual fraction of the original cell population is inversely proportional to the amount of preparation added. There are indications of inhibition of cell division as well as the more overt cytopathic effects. In the early stages of incubation with the toxin preparation, dividing cells are present and as the toxic effect becomes manifest few if any dividing cells or mitotic figures are seen. Although the cultural control is not shown, all of the cells appeared normal throughout the 3-day exposure period.

Thermostability, To determine the heat stability of the toxin preparations, the cytotoxicity of heated and wheated aqueous solutions of these materials were compared. The samples were placed in a boiling-water bath for $30 \mathrm{~min}$ and then immediately cooled to room temperature. This procedure is commonly used to inactivate the hemolysins. H.Ep\#2 cells were challenged with serial twofold dilutions of each preparation, with the highest concentration representing $200 \mu \mathrm{g}$ of preparation per $\mathrm{ml}$ of culture fluid (EBM with $20 \%$ human serum). In all experiments, readings were made at the end of the 48-hour incubation period because when the incubation period was extended to 7 clays with a change of medium on the third and fifth days the results were essentially similar. Since in all instances culture controls showed no adverse effects within this interval, any differences shown by the cultures inoculated with test preparations can be properly attributed to the factor(s) or substance(s) under study.

The data (Table 1) indicate that the cytotoxic material in each of the three preparations tested is thermolabile under the conditions of the experiment.

Table 1. Effect of heating and state of purification of enterotoxin preparations on the induction of cytopathology on H.Ep\#2 cells.

\begin{tabular}{|c|c|c|c|c|c|c|}
\hline \multirow{2}{*}{$\begin{array}{l}\text { Final concestration of } \\
\text { preparation, } \mu \mathrm{gg} / \mathrm{ml} \text { of } \\
\text { culture fluid }\end{array}$} & \multicolumn{2}{|c|}{ PB8A } & \multicolumn{2}{|c|}{ PB9B } & \multicolumn{2}{|c|}{ D2 } \\
\hline & Heated & Not heated & Heated & Not heated & Heaterl & Not heated \\
\hline 200 & + & ++++ & - & \pm & - & \pm \\
\hline 100 & + & ++++ & - & 上 & - & \pm \\
\hline 50 & - & +++ & - & - & - & - \\
\hline 25 & - & ++ & - & - & - & - \\
\hline 12.5 & - & - & - & - & - & - \\
\hline 6.3 & - & - & - & - & - & - \\
\hline 3.1 & - & - & - & - & - & - \\
\hline 1.6 & - & - & - & - & - & - \\
\hline
\end{tabular}

Legend: $++++=$ all cells damaged

$+++=50 \%$ or more damaged, monolayer irregular

$++=$ cells appear degenerated, monolayer irregular, cells at edge retracted

$+=$ good monolayer, cells at edge retracted and degenerated

$-=$ cells resemble control culture

$\pm=$ doubtful reaction 


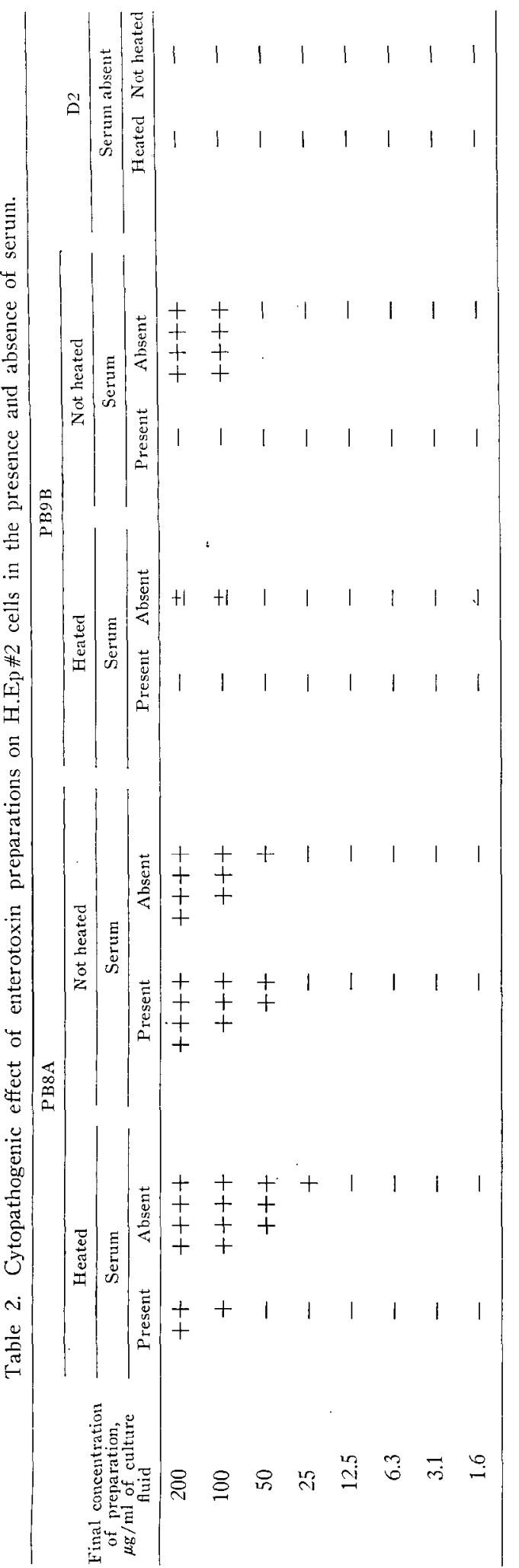

State of purification. Preparation D2 is more highly purified than $\mathrm{PB} 9 \mathrm{~B}$, and $\mathrm{PB} 9 \mathrm{~B}$ is purer than $\mathrm{PB} 8 \mathrm{~A}$, both $\mathrm{D} 2$ and $\mathrm{PB} 9 \mathrm{~B}$ being made from the PB8A material. A comparison of the cytotoxicity of these three preparations in Table 1 indicates that loss of this activity occurs with purification, the loss of cytotoxicity being most malked between the PB8A and the PB9B preparations.

Fffect of serum. Recause of the thermolahility of the cytotoxic material and its loss with purification of enterotoxin it is questionable that the material producing the cytotoxicity is the enterotoxin. In an attempt to increase the sensitivity of the test so as to detect the thermostable enterotoxin, serum was onitted from the tissue-culture maintenance medium. H.Ep\#2 cells were propagated in EBM containing calf serum, and the toxin titrations were carried out in Medium 199 with and without calf serum. Under these conditions the cytotoxicity of the three enterotoxin preparations of varying degres of purity, heated and unheated, is compared in Table 2. The more highly purified D2 preparation, because of its limited availability, was tested only in the absence of serum.

With PB8A preparation that was not heated, no significant difference in sensitivity is observed in either the presence or absence of serum. However, the heated material of the same preparation exerted a more marked effect in the absence of serum. With the more purified PB9B preparation, not heated, an increased sensitivity of the test in the absence of serum is indicated and a questionable increase in sensitivity is noted with the heated preparation in the absence of serum. An even more marked progressive decrease in cytotoxicity is observed with purification of the toxin preparation when no serum is used in the tissueculture medium than has been shown with serum present.

Comparison of cell lines. Tables 1 and 2 present data obtained from experiments using $H$.E $\# 2$ cells. For comparison, Table 3 illustrates the effect of two of the toxin preparations on cell cultures of strain HeLa. HeLa cells were propagated in EBM with $20 \%$ human serum and changed to Medium 199 containing no serum for the test. As with the H.Ep\#2 cells the cytotoxic component of the PB8A preparation is thermolabile whereas no toxic effect is noted with the more highly purified material PB9B. It should be pointed out that results were similar with human heart cells under conditions similar to those described here except that the titration was carricd out in the presence of $10 \%$ human serum.

Attempted neutralization with enterotoxin "specific" antibody. Using a serial twofold dilution 
Table 3. Cytopathogenic effect of enterotoxin preparations on HeLa cells on serum-free medium.

\begin{tabular}{|c|c|c|c|c|}
\hline \multirow{2}{*}{$\begin{array}{c}\text { Final concentration of } \\
\text { preparation, } \mu \mathrm{g} / \mathrm{ml} \text { of } \\
\text { culture fluid }\end{array}$} & \multicolumn{2}{|c|}{ PB8A } & \multicolumn{2}{|c|}{ PB9B } \\
\hline & Heated & Not heated & Heated & Not heated \\
\hline 200 & ++++ & ++++ & - & - \\
\hline 100 & + & $+\frac{1}{1}+$ & - & - \\
\hline 50 & - & + & - & - \\
\hline 25 & - & - & - & - \\
\hline 12.5 & - & - & - & - \\
\hline 6.3 & - & - & - & - \\
\hline
\end{tabular}

scheclule based on known antitoxic activity of the serum as tested in monkeys and a minimum cytotoxic dose of preparation PB8A, the toxinantitoxin mixtures were incubated $6 \mathrm{hr}$ at $37^{\circ} \mathrm{C}$ and overnight at $4^{\circ} \mathrm{C}$. Cultures were then inoculated, incubated at $37^{\circ} \mathrm{C}$, and read at 24,48 , and $72 \mathrm{hr}$.

Several experiments of this kind failed to show modification of the cytotoxic effect of the PB8A preparation by the serum. Several possible explanations may be offered. It is possible that the amount of antiserum used was too small, although concentrations were increased with each successive trial. The antiserum may not have containerl antibody against the cytotoxin, which would suggest that the cytotoxin differs from the enterotoxin. Another possibility was that the antigenantibody complex dissociated because of dilution when adderl to the culture or because it was unstable in the presence of the tissue-culture cells.

\section{DISCUSSION}

The multifactorial nature of the enterotoxin problem points to the possibility that a single factor may be responsible for more than one manifestation or that more than one factor may produce a single effect. In addition it is well known that the characterization of a substance may be limited by its sensitivity to adverse conditions, i.e., treatment with an acid, base, or organic solvent may produce a fundamental change resulting in a loss of original characteristics such as water solubility or specific biological activity.

On the basis of the reaction to heat the results presented suggest that the cytotoxic component of the preparations examined differs from the enterotoxin. Sinilarly it appears to be diminished or lost as purification of the enterotoxin proceeds. The failure to show neutralization of the cytotoxic princifle by enterotoxin-"specific" anti- serum, though inconclusive, supports the suggestion that the cytotoxin and enterotoxin are clistinct entities. Based on the results of early experiments indicating that there may be differences in cytotoxicity between enterotoxigenic and nonenterotoxigenic strains of staphylococci, the tissueculture system may be of some value if the cytotoxin can be shown to be common only to enterotoxigenic strains. It is mentioned that strain $196 \mathrm{E}$ enterotoxin preparation exerted a well-defined cytotoxic effect on human heart cells when the material was heated although no tests were made with the same preparation not heated.

Considering the possible role of the hemolysins in these experiments, the toxicity of alpha-hemolysin to skin cultures has been reported (Lawrence, 1959). The heat lability of cytotoxin implies that some, if not all, of the toxic effect might be attributed to a hemolysin-like material in the crude preparation. The fact that some activity is left after heating and that no demonstrable loss on heating occurs when titrated against H.Ep\#2 cells in the absence of serum (Table 2), the possibility remains that an additional thermostable toxin is present in the relatively crude preparation.

A few preliminary experimental results obtained with fluorescent antibody technique imply that there is in the toxin preparation an antigenic component that localizes in the cytoplasm of the tissue cells. Thus, if the cytopathogenic effect parallels the anount of material in the cell it would be possible to state that the cytotoxic material has been fixed in the cell. There were indications that this may be the case. It is planned to repeat the experiment after. attempting to adsorb out the nonspecific reactants from 
the antiserum since the enterotoxin preparations used were relatively crude.

There is no ready explanation for the apparent differences between these studies and those reported in a similar study already cited (Guerin et al., 1961). It is possible that these may be concerned with differences in technique in either the preparation of toxins or the use of tissue culture.

\section{ACKNOWLEDGMENTS}

Thanks are due Dr. Francis E. Payne, Assistant Professor of Epidemiology; Dr. Warren C. Eveland, for assistance in the fluorescent antibody experiments; Dr. Dónald J. Merchant, who furnished the cultures; and Seymour L. Kirschner, Judy Yesner, and Barbara Sattinger. The work was sponsored by the Commission on Environmental Hygiene of the Armed Forces Epidemiological Board and supported, in part, by the Office of the Surgeon General, Department of Army under contract No. DA-49-007-MD-280 with The University of Michigan.

\section{REFERENCES}

Allen, C. W. 1961. Unpublished studies.

Bergtoll, M. S., H. Sugiyama, and G. M. Dack. 1959. Arch. Biochent. Biophys. 85, 62.
Bergdoll, M. S. 1960a, b. Personal communications.

Casman, E. P. 1958. Serologic studies of staphylococcal enterotoxin. Public Health Reports 73, 599.

Casman, E. P. 1960. Further serological studies of staphylococcal enterotoxin. J. Bactoriol. 79, 849.

Guerin, M. H., A. W. Jackson, and J. F. Morgan. 1961. Susceptibility of tissue cultures to purified staphylococcal toxins. Abstr. Program Twelfth Ann. Meeting of the Tissue Culture Assoc. 37.

Lamanna, Carl. 1959. The most poisonous poison. Science 130, 763.

Lawrence, J. C. 1959. Some effects of staphylococcal and streptococcal toxins upon mammalian skin in tissue culture. Brit. I. Extl. Pathol. 40, 8.

Schantz, E. J. 1961. Personal communication.

Sugiyama, H., M. S. Bergdoll, and C. M. Dack. 1960. In vitro studies on staphylococcal enterotoxin production. I. Bacteriol. 80, 265.

Vicari, G., A. L. Olitzki, and Z. Olitzki. 1960. The action of the thermolabile toxin of Shigella dysenteriae on cells cultivated in vitro. Brit. J. Exptl. Pathol. 41, 179. 